Original Article

\title{
Effect of foot anthropometric measurements on postural stability
}

\author{
Seda Sertel Meyvaci ${ }^{1}$ - Turgut Meyvaci $^{2} \cdot$ Rengin Kosif $^{1} \cdot$ Murat Diramali $^{1} \cdot$ Handan Ankarali $^{\mathbf{3}}$ \\ ${ }^{1}$ Department of Anatomy, Bolu Abant Izzet Baysal University, Faculty of Medicine, Bolu, Turkey \\ ${ }^{2}$ Family Medicine Physician, Semerkant Family Health Center, Bolu, Turkey \\ ${ }^{3}$ Department of Biostatistics and Medical Informatics, Istanbul Medeniyet University, Faculty of Medicine, Istanbul, \\ Turkey
}

\section{ABSTRACT}

Aim: To examine the effect of foot anthropometric measurements and body sizes of young male adults with normal posture on balance.

Methods: In this study, the effect of body size and foot anthropometric measurements of 112 young male adults with normal posture on balance was investigated. The foot and body parameters of the cases were measured. The static and the dynamic balance tests were evaluated according to the dominant foot in each case. The parameters that affected balance were determined and the variables were taken to the model. In addition, the significance levels that defined the effects of the properties examined in relation with the balance were also calculated.

Results: When the findings were evaluated, it was determined that the effect of the foot parameters other than the foot length, and the effect of 15 body parameters other than the biiliac diameter, trochanteric height, and right upper extremity length on balance performance was significant. The balance test performance was predicted with success ranging from $7.8 \%$ to $43 \%$ with the parameters included in the model.

Conclusion: In this study, the fact that the relation between the foot anthropometric and body dimensions and functional balance performances of young male adults was found to be significant shows that this relation must be considered in the creation of a normative database on balance, and in clinical studies that will be conducted on the subject.

Keywords: Foot, postural balance, anthropometry, body measures, young adult, male.

(C) 2020 experimentalbiomedicalresearch.com

\section{Seda Sertel Meyvaci,}

Department of Anatomy, Bolu Abant Izzet Baysal University, Faculty of Medicine, Bolu, Turkey

E-mail: sedasertelmeyvaci@gmail.com

Received: 2020-05-06 / Revisions: 2020-05-20

Accepted: 2020-05-23 / Publication Date: 2020-06-13

\section{Introduction}

As a measurement technique in the human body, anthropometry can be defined as a quantitative expression technique of the shape of the human body [1].

Today, anthropometry is considered as the most portable, universally applicable, cheap and noninvasive technique to evaluate the size, proportions and composition of the human body [2]. With the help of this technique, especially individual differences like age and gender in the human body, and population 
differences variables were evaluated in previous studies [3,4].

Anthropometric assessments in the human body contains the measurements of circumferences, height, diameter, and fat mass tissue. When the studies in the literature were examined, many studies using these anthropometric measurement methods were identified $[5,6]$. However, the individual anthropometric differences that were assessed in these studies, which evaluated mostly body components and positions, were limited with height, weight and Body Mass Index (BMI), and did not assess other anthropometric changes $[7,8]$.

It is necessary to evaluate the results of studies according to anthropometric differences, because there will be changes in individual body components even if the study is limited with height, weight and BMI in the planning of the previous studies.

In the present study, the purpose was to examine the effect of foot anthropometric measurements and body sizes of young male adults with normal posture on balance.

\section{Materials and Methods}

The participants of the study were selected randomly from among the volunteers who were educated at or who worked at Bolu Abant Izzet Baysal University, and those who fit the inclusion criteria were included in the study. A total of 112 volunteering men that had an 18-25 age range and a BMI in normal limits were included in the study.

Considering the gender and age selection of the participants, the different hormonal cycle of every woman, difficult to standardize, which can cause changes in the musculoskeletal system affecting our balance performance results, only young male cases were included in our study, and their characteristics were evaluated.

\section{The selection criteria for the participants were:}

Inclusion criteria: Not having neurological or orthopedic disease that might cause balance disorder. Not having foot deformity. Not have any past surgery that might affect the foot and musculoskeletal system.

Having normal posture and asymptomatic status.

Having BMI within normal limits (18.50-24.9 $\mathrm{kg} / \mathrm{m}^{2}$ ).

Being between the ages of 18 and 25 .

Having male gender.

Not having sports-doing history.

Being volunteer to take part in the study.

Exclusion criteria: Having a neurological or orthopedic disease that might cause balance disorder. Having foot deformity. Having past surgery that might affect the foot and musculoskeletal system.

Not having normal posture and asymptomatic status.

Not having the BMI scores within the normal limits.

Being between the ages of 18 and 25 .

Having female gender.

Having sports-doing history.

Not volunteering to participate in the study.

This study was conducted in accordance with the rules of the Declaration of Helsinki. Written informed consent was obtained from each participant. The rights of the subjects were protected. It was approved by the Bolu Abant Izzet Baysal University Clinical Researches Ethics Committee Approval, Decision No:2018/91.

\section{Measurements}

In the present study, the parameters and balance tests of the foot and body dimensions of the cases were evaluated. In addition, posture evaluation of the cases were examined by using 
posture analysis by visual observation method. To determine the parameters of the foot, body dimensions and the deformity status of the cases, the measurements and evaluations were made by using a digital caliper, digital goniometer, height meter, length meter, tape measure ruler, and foot-graphics device. All the measurements were performed by the same evaluator and balance performance tests were performed under doctor's supervision. The measurements were recorded in millimeters $(\mathrm{mm})$ or degrees. In addition, for each case, age, height (stature), weight, BMI, dominant hand, dominant foot and all measurements were recorded in Excel.

\section{Foot Parameters}

The names and abbreviations of the foot parameters that were measured are given below. All measurements were made with a Digital Caliper [9-11].

1. Foot Length (FL)

2. Foot Width (FW)

3. Foot Heel Width (FHW)

4. Foot Height (FH)

5. Medial Malleoli Height (FMH)

6. Lateral Malleoli Height (FLH)

7. Height of Metatarsophalangeal Joint at First Toe (FM1)

8. Height of Metatarsophalangeal Joint at Fifth Toe (FM5)

9. Instep Apex Height (FAH)

10. Navicular Height (FNH)

\section{Body Parameters}

The names and abbreviations of the 18 body parameters that were measured are given below [11-13].

1. Right Upper Extremity Length (RUL)

2. Left Upper Extremity Length (LUL)

3. Lower Extremity Length (LL)

4. Subtalar Joint Angle (SJA)

5. Feet Opening Angle (OA)

6. Acromial Height (AH)

7. Trochanteric Height (TH)
8. Patellar Height $(\mathrm{PH})$

9. Trunk Length (TrL)

10. Thigh Length (ThL)

11. Shank Length (SL)

12. Biacromial Diameter (BAD)

13. Biiliac Diameter (BID)

14. Bitrochanteric Diameter (BTD)

15. Bimalleolar Diameter (BMD)

16. Chest Circumference (CC)

17. Waist Circumference (WC)

18. Hips Circumference (HC)

\section{Balance Tests}

In the present study, each case was tested for functional reach, flamingo balance test, which is a static balance test, and time-up and go (TUG), which is a dynamic balance test, 10 meter walk (10 M), and Y-balance test; and the results were evaluated according to the dominant foot. In the TUG and $10 \mathrm{M}$ test, the participants were asked to walk at the highest speed in a previously measured limited area.

1. Flamingo Balance Test: The test was applied for both lower extremities. The results were evaluated according to the dominant (FB) and non-dominant (FB-N) side [14].

2. Y Balance Test: The test was applied to both lower extremities. The anterior, medial, lateral components of the test were evaluated according to dominant (YA, YM, YL) and non-dominant (YA-N, YM-N, YL-N) side $[15,16]$.

3. Time-up and Go Test (TUG): Since it is a performance to which both lower extremities take part in, it was not evaluated according to dominant side [17].

4. 10-meter Walk Test $(10 \mathrm{M})$ : Since it is a performance to which both lower extremities take part in, it was not evaluated according to dominant side [18].

5. Functional Reach Test: The test was applied to the right (RFR) and left (LFR) upper extremities [19]. 


\section{Statistical Analysis}

The descriptive statistics of the data were calculated as mean, Standard Deviation (SD) and quartile values. Multiple linear regression model with forward selection methods was used for the determination of the effects of body sizes and foot anthropometric measures on balance. Statistically significant level was accepted as $P<0.05$.

\section{Results}

The descriptive statistical values of the numerical variables of the cases included in the evaluations were examined, and the demographic characteristics of them were determined (Table 1).

When we examined all the cases in terms of dominant foot, the dominant foot of 96 cases among the 112 cases was identified as the right

Table 1. The demographic characteristics of the cases.

\begin{tabular}{|c|c|c|c|c|c|c|}
\hline \multirow{2}{*}{$\begin{array}{l}\text { Demographic } \\
\text { Characteristics }\end{array}$} & \multirow{2}{*}{$\mathbf{N}$} & \multirow{2}{*}{ Mean } & \multirow{2}{*}{$\begin{array}{l}\text { Standard } \\
\text { Deviation }\end{array}$} & \multicolumn{3}{|c|}{ Percentiles } \\
\hline & & & & 25 & 50 & 75 \\
\hline Age (years) & 112 & 20.31 & 1.95 & 19.00 & 20.00 & 21.75 \\
\hline Height $(\mathrm{cm})$ & 112 & 176.09 & 6.13 & 172.00 & 176.35 & 179.95 \\
\hline Weight (kg) & 112 & 70.97 & 7.85 & 64.77 & 71.10 & 75.99 \\
\hline BMI (kg/m²) & 112 & 22.85 & 1.78 & 21.24 & 23.03 & 24.54 \\
\hline
\end{tabular}

Table 2. The descriptive values of the dominant and non-dominant foot of the cases.

\begin{tabular}{|c|c|c|c|c|c|c|c|}
\hline \multirow{2}{*}{ Foot Parameters (mm) } & \multirow{2}{*}{ Dominance Status } & \multirow{2}{*}{$\mathbf{N}$} & \multirow{2}{*}{ Mean } & \multirow{2}{*}{$\begin{array}{l}\text { Standard } \\
\text { Deviation }\end{array}$} & \multicolumn{3}{|c|}{ Percentiles } \\
\hline & & & & & 25 & 50 & 75 \\
\hline \multirow{2}{*}{ FL } & dominant & 112 & 26.30 & 1.27 & 25.60 & 26.09 & 27.32 \\
\hline & non-dominant & 112 & 26.38 & 1.23 & 25.60 & 26.35 & 27.22 \\
\hline \multirow{2}{*}{ FW } & dominant & 112 & 11.35 & 0.91 & 10.06 & 10.37 & 10.84 \\
\hline & non-dominant & 112 & 10.51 & 0.55 & 10.12 & 10.54 & 10.94 \\
\hline \multirow{2}{*}{ FHW } & dominant & 112 & 6.27 & 0.48 & 5.98 & 6.31 & 6.62 \\
\hline & non-dominant & 112 & 6.35 & 0.49 & 6.03 & 6.34 & 6.67 \\
\hline \multirow{2}{*}{ FMH } & dominant & 112 & 8.44 & 0.63 & 8.00 & 8.45 & 8.90 \\
\hline & non-dominant & 112 & 8.45 & 0.62 & 8.00 & 8.50 & 9.00 \\
\hline \multirow{2}{*}{ FLH } & dominant & 112 & 7.13 & 0.66 & 6.80 & 7.20 & 7.50 \\
\hline & non-dominant & 112 & 7.16 & 0.57 & 6.73 & 7.15 & 7.50 \\
\hline \multirow{2}{*}{ FM1 } & dominant & 112 & 3.33 & 0.41 & 3.10 & 3.30 & 3.50 \\
\hline & non-dominant & 112 & 3.34 & 1.02 & 3.10 & 3.20 & 3.40 \\
\hline \multirow{2}{*}{ FM5 } & dominant & 112 & 2.24 & 0.54 & 2.10 & 2.20 & 2.30 \\
\hline & non-dominant & 112 & 2.24 & 0.55 & 2.00 & 2.20 & 2.30 \\
\hline \multirow{2}{*}{ FAH } & dominant & 112 & 7.15 & 0.49 & 6.80 & 7.10 & 7.50 \\
\hline & non-dominant & 112 & 7.10 & 0.50 & 6.73 & 7.05 & 7.50 \\
\hline \multirow{2}{*}{ FNH } & dominant & 112 & 4.83 & 0.67 & 4.40 & 4.90 & 5.20 \\
\hline & non-dominant & 112 & 4.77 & 0.68 & 4.30 & 4.80 & 5.20 \\
\hline FH & right side & 112 & 7.12 & 0.54 & 6.73 & 7.20 & 7.50 \\
\hline
\end{tabular}


foot, and the dominant foot of 16 cases was identified as the left foot. The descriptive values of the foot parameters were assessed as dominant foot and non-dominant foot. The FH parameter was measured from one place, on the right side of the case (Table 2).

The descriptive values of all the cases except for the feet were assessed, and are given in Table 3. The descriptive values of the static and dynamic balance test measurements of all the cases were evaluated according to the dominance status of the lower extremities (Table 4).

We examined the parameters that affected static balance tests. It was determined that FM1 and FAH, which are the foot parameters, together with LL, SJA and OA body parameters had effects on the dominant side in the FH balance test $(P<0.05)$. Since the $\mathrm{P}$ value of the foot FMH parameter was $P<0.10$ in the resulting model, it was left in the model because it would affect the model significantly when it was discarded from the model. The effect of this variable was also important on balance. When the degree of importance of the parameters that were included in the model in predicting the FH test was examined, it was determined that the FM1 parameter, which had the highest importance, had the highest effect on $\mathrm{FH}$ balance. The FH balance test is estimated with $25.9 \%$ success with the 6 parameters included in this model (Table 5). When all the systemic and anatomical variables in the body that are effective on balance were considered, it

Table 3. The descriptive values of the body anthropometric measurements of the cases.

\begin{tabular}{|l|c|c|c|c|c|c|}
\hline \multirow{2}{*}{$\begin{array}{l}\text { Body } \\
\text { anthropometric } \\
\text { measurements }\end{array}$} & $\mathbf{N}$ & \multirow{2}{*}{ Mean } & \multirow{2}{*}{$\begin{array}{c}\text { Standard } \\
\text { Deviation }\end{array}$} & $\mathbf{2 5}$ & $\mathbf{5 0}$ & $\mathbf{7 5}$ \\
\cline { 5 - 7 } & & & & & & \multicolumn{3}{|c|}{ Percentiles } \\
\hline RUL & 112 & 78.59 & 3.71 & 76.48 & 78.65 & 80.88 \\
\hline LUL & 112 & 78.53 & 3.69 & 76.05 & 78.75 & 80.70 \\
\hline LL & 112 & 91.93 & 4.52 & 89.35 & 91.50 & 94.95 \\
\hline OJA & 112 & 2.15 & 1.08 & 1.00 & 2.00 & 3.00 \\
\hline AH & 112 & 19.09 & 5.65 & 14.96 & 18.38 & 22.80 \\
\hline TH & 112 & 144.91 & 5.43 & 141.85 & 144.50 & 147.88 \\
\hline PH & 112 & 91.09 & 6.53 & 88.35 & 91.50 & 94.15 \\
\hline TrL & 112 & 49.62 & 6.12 & 48.00 & 49.95 & 51.40 \\
\hline ThL & 112 & 53.08 & 3.63 & 51.00 & 53.40 & 55.50 \\
\hline SL & 112 & 42.02 & 3.34 & 40.00 & 41.85 & 44.08 \\
\hline BAD & 112 & 43.44 & 5.97 & 41.08 & 43.00 & 44.30 \\
\hline BID & 112 & 40.58 & 1.60 & 39.70 & 40.49 & 41.60 \\
\hline BTD & 112 & 28.93 & 2.05 & 27.68 & 29.17 & 30.18 \\
\hline BMD & 112 & 33.18 & 1.82 & 32.23 & 33.22 & 34.27 \\
\hline CC & 112 & 7.45 & 1.11 & 7.05 & 7.29 & 7.61 \\
\hline WC & 112 & 91.16 & 5.35 & 88.00 & 91.00 & 95.00 \\
\hline HC & 112 & 77.72 & 7.13 & 74.85 & 78.00 & 82.45 \\
\hline
\end{tabular}


becomes important to reach this high predictive value as a result of measuring the 6 parameters. It was determined that the foot parameter FM1 and $\mathrm{PH}, \mathrm{SJA}$ and $\mathrm{OA}$ body parameters had effect on the FH-N balance parameter $(P<0.05)$. Since the $\mathrm{P}$ value of the foot $\mathrm{FAH}$ parameter was $<0.10$ in the resulting model, it was left in the model because it would affect the model significantly when it was discarded from the model. The effect of this variable was also important on balance. When the degree of importance of the parameters that were included in the model in predicting the $\mathrm{FH}-\mathrm{N}$ test was examined, it was determined that the FM1 parameter, which had the highest importance, had the highest effect on FH-N balance. The FH-N balance test is estimated with $20.6 \%$ success with the 5 parameters included in this model (Table 6).

The foot and body parameter of the $\mathrm{Y}$ balance test, which is one of the dynamic balance tests, affecting the YA performance, could not be determined, in other words, there are no parameters in this model to predict YA $\left(\mathrm{R}^{2}=0 \%\right)$. Only the FW affects the YM balance, and it was also determined that the $\mathrm{CC}$ parameter might have a significant effect on the model $(P<0.10)$. The YM balance test is estimated with $7.8 \%$ success with the 2 parameters included in this model.

When the YL balance was examined, it was found that it only affects the FW. It was also found that SJA and FHW might have an effect on the model $(P<0.10)$. The YL balance test is estimated with $10.5 \%$ success with the 3 parameters included in this model (Table 7). When the $\mathrm{Y}$ balance test, which is the other balance test, was examined, it was determined in the non-dominant extremity that it was determined that the foot parameters, FMH and FW, which affected YA-N performance, and $\mathrm{CC}$ and $\mathrm{HC}$ from the body parameters. It was determined that the FLH, FM5, OA, ThL and BMI parameters would affect the YA-N balance test results significantly in the resulting model (Table 8). When the degree of importance of the parameters that were included in the model in predicting the YA-N test was examined, the $\mathrm{CC}$ parameter, which had the highest importance, had the highest

Table 4. The descriptive values of the static and dynamic balance test measurements of the cases.

\begin{tabular}{|c|c|c|c|c|c|c|c|}
\hline \multirow{2}{*}{\multicolumn{2}{|c|}{ Balance Tests }} & \multirow{2}{*}{$\mathbf{N}$} & \multirow{2}{*}{ Mean } & \multirow{2}{*}{$\begin{array}{l}\text { Standard } \\
\text { Deviation }\end{array}$} & \multicolumn{3}{|c|}{ Percentiles } \\
\hline & & & & & 25 & 50 & 75 \\
\hline \multicolumn{2}{|l|}{ FH } & 112 & 7.79 & 5.47 & 3.25 & 7.00 & 11.75 \\
\hline \multicolumn{2}{|l|}{ FH-N } & 112 & 7.68 & 5.51 & 3.00 & 7.00 & 11.00 \\
\hline \multirow{6}{*}{$\begin{array}{l}\text { Y } \\
\text { Balance }\end{array}$} & YA & 112 & 83.37 & 10.85 & 75.47 & 83.65 & 90.31 \\
\hline & YM & 112 & 60.44 & 12.24 & 51.90 & 60.71 & 68.58 \\
\hline & YL & 112 & 72.89 & 14.69 & 63.52 & 72.47 & 84.26 \\
\hline & YA-N & 112 & 82.90 & 13.40 & 75.76 & 83.10 & 90.41 \\
\hline & YM-N & 112 & 62.99 & 10.77 & 55.86 & 63.69 & 69.87 \\
\hline & YL-N & 112 & 74.53 & 12.60 & 64.09 & 74.41 & 85.09 \\
\hline \multicolumn{2}{|l|}{ TUG } & 112 & 5.37 & 0.96 & 4.70 & 5.17 & 6.11 \\
\hline \multicolumn{2}{|l|}{$10 \mathrm{M}$} & 112 & 5.23 & 0.67 & 4.71 & 5.21 & 5.76 \\
\hline \multicolumn{2}{|l|}{ RFR } & 112 & 27.65 & 8.84 & 20.72 & 28.45 & 34.09 \\
\hline \multicolumn{2}{|l|}{ LFR } & 112 & 26.37 & 8.45 & 19.33 & 27.19 & 32.28 \\
\hline
\end{tabular}


effect on the YA-N balance. The YA-N balance test is estimated with $21.2 \%$ success with the 9 parameters included in this model.

Only FW, which is among the foot parameters, and the SL, CC and BMI, which are among the body parameters, affect the YM-N balance. It was determined that the FM5 parameter has a significant effect on the model $(P<0.10)$. When the degree of importance of the parameters that were included in the model in predicting the YM-N test was examined, the CC parameter, which has the highest significance, has the highest effect on the YM-N balance. The YM$\mathrm{N}$ balance test is estimated with $15.0 \%$ success with the 5 parameters included in this model. When the YL-N balance was examined, it was determined that only the FW, which is among the foot parameters, and the CC, SL, SJA and BMI, which are among the body parameters, affect it. It was determined that only ThL might have an effect on the model $(P<0.10)$. When the degree of importance in predicting the YL-N test was examined, it was determined that the CC parameter, which had the highest significance, had the highest effect on the YL$\mathrm{N}$ balance. The YL-N balance test is estimated with $14.6 \%$ success with the 6 parameters included in this model (Table 8).

Table 5. The effect of foot and body parameters on the FH test.

\begin{tabular}{|l|c|c|c|c|c|c|c|}
\hline \multirow{2}{*}{$\begin{array}{l}\text { Model term } \\
\text { FH }\end{array}$} & \multirow{2}{*}{ Coefficient } & \multirow{2}{*}{ SD \pm} & \multirow{2}{*}{$\mathbf{t}$} & $\boldsymbol{P}$ & \multicolumn{2}{|c|}{ 95\% Confidence interval } & \multirow{2}{*}{ Importance } \\
\cline { 5 - 7 } Intercept & -13.531 & 9.836 & -1.376 & 0.172 & -33.034 & 5.972 & \\
\hline FM1 & 6.715 & 1.701 & 3.948 & 0.0001 & 3.342 & 10.087 & 0.329 \\
\hline FAH & -4.278 & 1.348 & -3.172 & 0.002 & -6.952 & -1.604 & 0.213 \\
\hline LL & 0.453 & 0.171 & 2.647 & 0.009 & 0.114 & 0.793 & 0.148 \\
\hline SJA & -1.109 & 0.438 & -2532 & 0.013 & -1.978 & -0.241 & 0.135 \\
\hline OA & -0.182 & 0.083 & -2.189 & 0.031 & -0.346 & -0.017 & 0.101 \\
\hline FMH & 1.899 & 1.016 & 1.869 & 0.064 & -0.116 & 3.914 & 0.074 \\
\hline
\end{tabular}

Table 6. The effect of foot and body parameters on the FH-N test.

\begin{tabular}{|l|c|c|c|c|c|c|c|}
\hline \multirow{2}{*}{$\begin{array}{l}\text { Model term } \\
\text { FH-N }\end{array}$} & \multirow{2}{*}{ Coefficient } & \multirow{2}{*}{ SD \pm} & \multirow{2}{*}{$\mathbf{t}$} & $\boldsymbol{P}$ & \multicolumn{2}{|c|}{$\mathbf{9 5 \%}$ Confidence interval } & \multirow{2}{*}{ Importance } \\
\cline { 5 - 7 } & & & & & Lower & Upper & \\
\hline Intercept & -20.218 & 10.314 & -1.960 & 0.053 & -40.666 & 0.230 & \\
\hline FM1 & 5.807 & 1.744 & 3.330 & 0.001 & 2.350 & 9.265 & 0.327 \\
\hline PH & 0.584 & 0.183 & 3.194 & 0.002 & 0.221 & 0.946 & 0.300 \\
\hline SJA & -1.032 & 0.460 & -2.244 & 0.027 & -1.944 & -0.120 & 0.148 \\
\hline OA & -0.177 & 0.084 & -2.100 & 0.038 & -0.344 & -0.010 & 0.130 \\
\hline FAH & -2.065 & 1.149 & -1.797 & 0.075 & -4.342 & 0.213 & 0.095 \\
\hline
\end{tabular}


Table 7. The effect of foot and body parameters on the Y balance test.

\begin{tabular}{|c|c|c|c|c|c|c|c|c|}
\hline \multirow{2}{*}{$\begin{array}{l}\text { Model } \\
\text { term } \\
\text { Y Balance }\end{array}$} & & \multirow{2}{*}{$\begin{array}{c}\text { Coefficien } \\
\mathbf{t}\end{array}$} & \multirow[t]{2}{*}{ \pm SD } & \multirow[t]{2}{*}{ t } & \multirow[t]{2}{*}{$\boldsymbol{P}$} & \multicolumn{2}{|c|}{$\begin{array}{l}\text { 95\% Confidence } \\
\text { interval }\end{array}$} & \multirow{2}{*}{$\begin{array}{c}\text { Importanc } \\
\text { e }\end{array}$} \\
\hline & & & & & & Lower & Upper & \\
\hline \multirow{3}{*}{ YM } & Intercept & -23.205 & 25.142 & -0.923 & 0.358 & -73.036 & 26.625 & \\
\hline & FW & 4.870 & 1.886 & 2.582 & 0.011 & 1.132 & 8.608 & 0.699 \\
\hline & $\mathrm{CC}$ & 0.361 & 0.213 & 1.696 & 0.093 & -0.061 & 0.782 & 0.301 \\
\hline \multirow{4}{*}{ YL } & Intercept & 37.262 & 26.073 & 1.429 & 0.156 & -14.418 & 88.942 & \\
\hline & FW & 7.073 & 2.261 & 3.128 & 0.002 & 2.591 & 11.556 & 0.585 \\
\hline & SJA & -2.368 & 1.268 & $\begin{array}{c}-1.868 \\
\end{array}$ & 0.064 & -4.881 & 0.145 & 0.208 \\
\hline & FHW & -5.265 & 2.829 & -1.861 & 0.065 & -10.872 & 0.343 & 0.207 \\
\hline
\end{tabular}

Table 8. The effect of foot and body parameters on the Y-N balance test.

\begin{tabular}{|c|c|c|c|c|c|c|c|c|}
\hline \multirow{2}{*}{$\begin{array}{l}\text { Model term } \\
\text { Y-N Balance }\end{array}$} & & \multirow{2}{*}{ Coefficient } & \multirow{2}{*}{ \pm SD } & \multirow{2}{*}{$\mathbf{t}$} & \multirow{2}{*}{$P$} & \multicolumn{2}{|c|}{ 95\% Confidence interval } & \multirow{2}{*}{ Importance } \\
\hline & & & & & & Lower & Upper & \\
\hline \multirow{10}{*}{ YA-N } & Intercept & 93.833 & 30.976 & 3.029 & 0.003 & 32.393 & 155.274 & \\
\hline & $\mathrm{CC}$ & 1.217 & 0.345 & 3.523 & 0.001 & 0.532 & 1.902 & 0.236 \\
\hline & FMH & -8.552 & 2.603 & -3.285 & 0.001 & -13.715 & -3.389 & 0.205 \\
\hline & HC & -0.842 & 0.339 & -2.484 & 0.015 & -1.515 & -0.170 & 0.117 \\
\hline & FW & 5.188 & 2.205 & 2.353 & 0.021 & 0.814 & 9.563 & 0.105 \\
\hline & FLH & 5.378 & 2.744 & 1.960 & 0.053 & -0.064 & 10.820 & 0.073 \\
\hline & $\mathbf{O A}$ & -0.412 & 0.213 & -1.935 & 0.056 & -0.833 & 0.010 & 0.071 \\
\hline & BMI & -2.182 & 1.137 & -1.919 & 0.058 & -4.436 & 0.073 & 0.070 \\
\hline & ThL & -0.683 & 0.379 & -1.802 & 0.075 & -1.434 & 0.069 & 0.062 \\
\hline & FM5 & 11.129 & 6.296 & 1.768 & 0.080 & -1.359 & 23.617 & 0.059 \\
\hline \multirow{6}{*}{ YM-N } & Intercept & -8.455 & 25.752 & -0.328 & 0.743 & -59.512 & 42.601 & \\
\hline & $\mathrm{CC}$ & 0.849 & 0.277 & 3.068 & 0.003 & 0.300 & 1.398 & 0.327 \\
\hline & FW & 4.637 & 1.726 & 2.687 & 0.008 & 1.216 & 8.058 & 0.251 \\
\hline & BMI & -1.872 & 0.840 & -2.228 & 0.028 & -3.538 & -0.206 & 0.172 \\
\hline & SL & -0.730 & 0.362 & -2.016 & 0.046 & -1.449 & -0.012 & 0.141 \\
\hline & FM5 & 9.029 & 5.100 & 1.770 & 0.080 & -1.083 & 19.141 & 0.109 \\
\hline \multirow{7}{*}{ YL-N } & Intercept & 51.095 & 29.546 & 1.729 & 0.087 & -7.490 & 109.679 & \\
\hline & $\mathrm{CC}$ & 1.022 & 0.334 & 3.062 & 0.003 & 0.360 & 1.683 & 0.254 \\
\hline & FW & 5.704 & 1.953 & 2.920 & 0.004 & 1.830 & 9.577 & 0.231 \\
\hline & BMI & -2.508 & 0.997 & -2.516 & 0.013 & -4.485 & -0.531 & 0.171 \\
\hline & SL & -1.010 & 0.430 & -2.350 & 0.021 & -1.863 & -0.158 & 0.149 \\
\hline & SJA & -2.348 & 1.072 & -2.191 & 0.031 & -4.474 & -0.223 & 0.130 \\
\hline & ThL & -0.558 & 0.360 & -1.550 & 0.124 & -1.272 & 0.156 & 0.065 \\
\hline
\end{tabular}


When the TUG balance was examined, only the $\mathrm{PH}, \mathrm{LL}$ and BAD, which are among the body parameters, and FHW, which is among the foot parameters, affect it. It was also determined that BTD, ThL, TrL and SJA might have an effect on the model $(P<0.10)$. When the degree of importance of the parameters that were included in the model in predicting the TUG test was examined, it was determined that the PH parameter, which had the highest importance, had the highest effect on the TUG balance. The TUG balance test is estimated with $32.0 \%$ success with 8 parameters included in this model (Table 9).
When the $10 \mathrm{M}$ balance was evaluated, it was determined that only the FNH, which is among foot parameters, affected it, and no body parameters affected it. It was also determined that FM5, FHW and BAD might have effect on the model $(P<0.10)$. When the significance level of the parameters that were included in the model in predicting the $10 \mathrm{M}$ test was examined, it was determined that the $\mathrm{FNH}$ parameter, which had the highest significance level, had the highest effect on the $10 \mathrm{M}$ balance. The $10 \mathrm{M}$ balance test is estimated with $15.0 \%$ success with the 4 parameters included in this model (Table 10).

Table 9. The effect of foot and body parameters on the TUG balance test.

\begin{tabular}{|c|c|c|c|c|c|c|c|}
\hline \multirow{2}{*}{$\begin{array}{l}\text { Model term } \\
\text { TUG }\end{array}$} & \multirow{2}{*}{ Coefficient } & \multirow{2}{*}{ \pm SD } & \multirow{2}{*}{$\mathbf{t}$} & \multirow{2}{*}{$\boldsymbol{P}$} & \multicolumn{2}{|c|}{ 95\% Confidence interval } & \multirow{2}{*}{ Importance } \\
\hline & & & & & Lower & Upper & \\
\hline Intercept & 6.369 & 2.496 & 2.552 & 0.012 & 1.418 & 11.319 & \\
\hline $\mathbf{P H}$ & 0.136 & 0.039 & 3.522 & 0.001 & 0.060 & 0.213 & 0.274 \\
\hline $\mathbf{L L}$ & -0.090 & 0.027 & -3.327 & 0.001 & -0.143 & -0.036 & 0.244 \\
\hline BAD & -0.118 & 0.054 & -2.189 & 0.031 & -0.225 & -0.011 & 0.106 \\
\hline FHW & 0.346 & 0.171 & 2.028 & 0.045 & 0.008 & 0.685 & 0.091 \\
\hline BTD & 0.095 & 0.051 & 1.876 & 0.064 & -0.005 & 0.195 & 0.078 \\
\hline ThL & 0.047 & 0.026 & 1.791 & 0.076 & -0.005 & 0.098 & 0.071 \\
\hline SJA & 0.134 & 0.076 & 1.774 & 0.079 & -0.016 & 0.285 & 0.070 \\
\hline TrL & -0.043 & 0.025 & -1.740 & 0.085 & -0.092 & 0.006 & 0.067 \\
\hline
\end{tabular}

Table 10. The effect of foot and body parameters on the $10 \mathrm{M}$ test.

\begin{tabular}{|l|c|c|c|c|c|c|c|}
\hline \multirow{2}{*}{$\begin{array}{l}\text { Model term } \\
\mathbf{1 0} \mathbf{*}\end{array}$} & \multirow{2}{*}{ Coefficient } & \multirow{2}{*}{ SD \pm} & \multirow{2}{*}{$\mathbf{t}$} & $\boldsymbol{P}$ & \multicolumn{2}{|c|}{$\mathbf{9 5 \%}$ Confidence interval } & \multirow{2}{*}{ Importance } \\
\cline { 1 - 4 } Intercept & 6.637 & 1.756 & 3.781 & 0.0001 & 3.157 & 10.118 & \\
\hline FNH & 0.248 & 0.096 & 2.586 & 0.011 & 0.058 & 0.438 & 0.421 \\
\hline FM5 & -0.587 & 0.309 & -1.902 & 0.060 & -1.200 & 0.025 & 0.228 \\
\hline BAD & -0.066 & 0.038 & -1.727 & 0.087 & -0.141 & 0.010 & 0.188 \\
\hline FHW & 0.216 & 0.134 & 1.615 & 0.109 & -0.049 & 0.481 & 0.164 \\
\hline
\end{tabular}


When the RFR test was examined, the effects of FNH and FAH, which are among foot parameters, and LUL, LL and OA, which are among the body parameters, were determined. The effect of BTD was not found to be at statistically significant level on the model. When the significance level of the parameters that were included in the model on predicting the RFR test was examined, it was determined that the LUL parameter, which had the highest significance level, had the highest effect on the RFR balance. The RFR balance test is estimated with $27.0 \%$ success with the 6 parameters included in this model (Table 11).
When the LFR test was evaluated, it was determined that the AH, CC, LUL, BTD, BAD, WC ve BMI, which are among the body parameters, and the $\mathrm{FNH}, \mathrm{FW}$ ve $\mathrm{FH}$, which are among the foot parameters, had effects. When the significance level of the parameters that were included in the model in predicting the LFR test was examined, it was determined that the FNH parameter, which had the highest significance level, had the highest effect on the LFR balance. The LFR balance test is estimated with $43.0 \%$ success with the 10 parameters included in this model (Table 12).

Table 11. The effect of foot and body parameters on the RFR test.

\begin{tabular}{|l|c|c|c|c|c|c|c|}
\hline $\begin{array}{l}\text { Model term } \\
\text { RFR }\end{array}$ & Coefficient & $\mathbf{S D} \pm$ & $\mathbf{t}$ & $\boldsymbol{P}$ & \multicolumn{2}{|c|}{ 95\% Confidence interval } & \multirow{2}{*}{ Importance } \\
\cline { 5 - 7 } Intercept & 48.488 & 18.893 & 2.566 & 0.012 & 11.027 & 85.950 & \\
\hline LUL & -0.839 & 0.282 & -2.975 & 0.004 & -1.399 & -0.280 & 0.239 \\
\hline FNH & -3.941 & 1.419 & -2.777 & 0.006 & -6.754 & -1.127 & 0.208 \\
\hline LL & 0.659 & 0.245 & 2.696 & 0.008 & 0.174 & 1.144 & 0.196 \\
\hline OA & 0.334 & 0.136 & 2.466 & 0.015 & 0.065 & 0.603 & 0.164 \\
\hline FAH & 3.669 & 1.821 & 2.014 & 0.047 & 0.058 & 7.280 & 0.110 \\
\hline BTD & 0.877 & 0.499 & -1.758 & 0.082 & -1.867 & 0.112 & 0.083 \\
\hline
\end{tabular}

Table 12. The effect of foot and body parameters on the LFR test.

\begin{tabular}{|c|c|c|c|c|c|c|c|}
\hline \multirow{2}{*}{$\begin{array}{l}\text { Model term } \\
\text { LFR }\end{array}$} & \multirow{2}{*}{ Coefficient } & \multirow{2}{*}{$\mathrm{SD} \pm$} & \multirow{2}{*}{$\mathbf{t}$} & \multirow{2}{*}{$\boldsymbol{P}$} & \multicolumn{2}{|c|}{ 95\% Confidence interval } & \multirow{2}{*}{ Importance } \\
\hline & & & & & Lower & Upper & \\
\hline Intercept & 9.001 & 21.085 & 0.427 & 0.670 & -32.831 & 50.832 & \\
\hline FNH & -6.451 & 1.228 & -5.253 & 0.0001 & -8.887 & -4.014 & 0.203 \\
\hline $\mathbf{A H}$ & 1.160 & 0.225 & 5.150 & 0.0001 & 0.713 & 1.607 & 0.195 \\
\hline BMI & 3.071 & 0.712 & 4.312 & 0.0001 & 1.658 & 4.483 & 0.137 \\
\hline $\mathrm{CC}$ & -0.714 & 0.203 & -3.513 & 0.001 & -1.117 & -0.311 & 0.091 \\
\hline LUL & -0.829 & 0.240 & -3.459 & 0.001 & -1.304 & -0.353 & 0.088 \\
\hline FW & -3.615 & 1.171 & -3.087 & 0.003 & -5.938 & -1.292 & 0.070 \\
\hline BTD & -1.371 & 0.486 & -2.822 & 0.006 & -2.336 & -0.407 & 0.059 \\
\hline FH & 4.240 & 1.589 & 2.668 & 0.009 & 1.087 & 7.393 & 0.052 \\
\hline BAD & 1.214 & 0.483 & 2.515 & 0.014 & 0.256 & 2.172 & 0.047 \\
\hline WC & -0.438 & 0.202 & -2.171 & 0.032 & -0.839 & -0.038 & 0.035 \\
\hline
\end{tabular}


When all of the systemic and anatomic variables of the body that are effective on balance were evaluated, it was determined that measuring these parameters is important in having high predictive value in studies that are based on performance like balance and in achieving accurate results.

\section{Discussion}

Anthropometric data provides information regarding the static dimensions of the human body in standard postures. Anthropometry has been used as the indicator of health status in national anthropometric sizing studies over years [20]. Knowing all the factors that might affect anthropometric measurements is important for accurate planning of studies, by considering individual anthropometric differences and obtaining accurate results in studies, and more data are necessary. These anthropometric measurements are affected by many factors which include age, height, weight, gender and ethnic origin. For this reason, many studies were conducted by considering the factors, which affect anthropometric measurements [21-23].

When the studies in the literature were examined, it was determined that many researchers considered the factors, which affected anthropometric measurements, and which limited these factors, especially age and gender, to obtain more accurate results [24-26]. Many researchers who are interested in anthropometric measurements conducted studies to standardize these values in their population by considering the racial differences and ethnicity [27].

In the present study, many anthropometric measurements of the foot and body were examined by limiting age, BMI and gender.

Many researchers who are interested in foot anthropometry conducted studies on foot measurements, shoe dimensions, foot print, plantar pressure, sex identification, age and stature estimation [28-31]. In these studies, most of the measurements were made with the help of calipers and measuring tapes in addition to radiography and computed tomography [9,32-34].

In the present study, which examined the effects of foot anthropometric measurements on balance, the foot parameters were measured bilaterally by using digital caliper.

When similarly-planned studies were examined, it was determined that some researchers examined the parameters like FL [12,34,35], FW [10,12,34], FHW [9,36], FH, FMH, FLH, FM1, FM5, FAH ve FNH $[9,10,28]$, which are among foot parameters, were investigated by some researchers. When the results were compared, it was determined that although some results were similar to ours, some other results were different. We believe that this might be due to the fact that researchers included different number of cases in their studies, and that the cases did not have the same age and population.

When the studies conducted on body parameters were examined, it was determined that stature, weight, upper and lower extremity lengths; body heights like $\mathrm{AH}, \mathrm{TH}, \mathrm{PH}$, and lengths of body parts like TrL, ThL, SL; diameter and circumference measurements, foot and hand measurements; anthropometric measurements like OA, SJA and BMI were evaluated by researchers [10,11,13,27,37]. As in these studies, in our study, body heights like stature, weight, RUL, LUL, LL, AH, TH, PH, height of body parts like TrL, ThL, SL, circumference measurements like $\mathrm{CC}$, WC, $\mathrm{HC}$, foot measurements and OA, SJA, BMI parameters were evaluated.

Among the studies, which necessitate that the physical participation of individuals like 
balance, which may affect the results, the studies assessing balance are important.

When other studies conducted in the fields of running, swimming and other sports that require balance-level performance were examined, many body anthropometric parameters were taken into account [7,37-39]. It was found that there are limited studies especially examining the relations between balance and foot and body anthropometric measurements [40,41]. In their study, Alonso et al. evaluated the balance parameters with the help of a device, and found that there was a relation among height, trunk-cephalic length, upper-limb length, and lower-limb length [40]. In their study, Keionen et al. examined the effect of foot parameters on balance, and concluded that there was a relation among heigth, hip-ground distance, and knee-ground distance and some balance parameters especially in foot width, heel width, and foot length [41]. In another study conducted by Moein and Movaseghi on female cases, no relation was detected about foot length parameter, although a relation was detected with the lower leg length parameter and balance [42]. In the present study, the effect of the foot parameters on balance was examined, together with other body parameters, and what effect it had on a performance like balance was investigated. When the findings were evaluated, it was determined that the other foot parameters except for the foot length, the effect of the body parameters except for the length of the right upper extremity, biiliac diameter, and trochanteric height had effects on balance performance. The foot width (0.699) had the highest significance among the foot parameters, and the chest circumference (0.327) among the body parameters had the highest significance. It was concluded that balance test performance can be predicted with the parameters included in the model with a success ranging from $7.8 \%$ to $43 \%$. In the present study, it was also found that especially BMI, chest, waist and hip circumference measurements had effects on the results of some balance tests.

\section{Conclusions}

Balance is defined as the ability to keeping the center of gravity of the body on the support center connected to a good functional postural control system. This complex nervous system process is fed with visual, auditory and somatosensorial stimuli. The resulting answer is a whole of neuromuscular stimulation reaching the musculoskeletal system [43].

Balance is controlled with the detection of the movements, positions and proprioceptive senses coming from the foot by adjusting them according to the environment with the central nervous system. As a result of our study, it was determined that the anthropometric of the foot and body had an effect on the balance results. In the present study, which included only male cases and in which the age range was limited to 18-25, normative data of balance were obtained and contributed to the literature by considering all the factors that might affect balance performance.

Which among the different foot and body parameters would affect static and dynamic functional balance tests was also determined in our study. In this respect, different parameters should be considered according to the test to be performed when selecting balance tests.

In the light of the obtained data in the present study, it was found that the relation between foot anthropometric and body measurements and functional balance performances of young male adults with normal posture is significant; and we believe that the results can be useful in evaluating and planning of future clinical studies. 


\section{Acknowledgments}

The authors would like to thank for the helps of intern physiotherapists and all volunteers who contributed to our research.

Funding: This study supported by Bolu Abant Izzet Baysal University Office of Scientific Research. Project No: 2018.08.01.1380.

Conflict of Interest: The authors declare that they have no conflict of interest.

Ethical statement: The study was conducted in accordance with the ethical approval of the University Ethics Committee. (Decision No:2018/91).

\section{ORCID iD of the author(s)}

Seda Sertel Meyvaci / 0000-0002-9450-145X

Turgut Meyvaci / 0000-0002-8836-1956

Rengin Kosif / 0000-0002-0334-1658

Murat Diramali / 0000-0001-5824-6159

Handan Ankarali / 0000-0002-3613-0523

\section{References}

[1]Kanchan T, Krishan K. Anthropometry of hand in sex determination of dismembered remains- A review of literature. J Forensic Leg Med. 2011; 18(1):14-17.

[2]Sen J, Ghosh S. Estimation of stature from foot length and foot breadth among the Rajbanshi: An indigenous population of North Bengal. Forensic Sci Int. 2008; 181(1-3):55.e1-55.e6.

[3]Kahn DM, Shaw RB. Aging of the Bony Orbit: A Three-Dimensional Computed Tomographic Study. Aesthetic Surg J. 2008; 28(3):258-64.

[4]Noble J, Flavel A, Aviv R, et al. Forensic anthropological standards for cranial sex estimation in Canada: preliminary results. Aust J Forensic Sci. 2019; 51(sup1):S1-S4.
[5]Lean MEJ, Han TS, Morrison CE. Waist circumference as a measure for indicating need for weight management. BMJ. 1995; 311(6998): 158.

[6]Mohammad YAA. Anthropometric characteristics of the hand based on laterality and sex among Jordanian. Int J Ind Ergon. 2004; 35(8):747-54.

[7]Hue O, Simoneau M, Marcotte J, et al. Body weight is a strong predictor of postural stability. Gait Posture. 2007; 26(1):32-38.

[8]Greve J, Alonso A, Bordini ACPG, et al. Correlation between body mass index and postural balance. Clinics. 2007; 62(6):71720.

[9]Zeybek G, Ergur I, Demiroglu Z. Stature and gender estimation using foot measurements. Forensic Sci Int. 2008; 181(1-3):54.e154.e5.

[10]Özaslan A, Işcan MY, Özaslan I, et al. Estimation of stature from body parts. Forensic Sci Int. 2003; 132(1):40-45.

[11] Kamal R, Yadav PK. Estimation of stature from different anthropometric measurements in Kori population of North India. Egypt J Forensic Sci. 2016; 6(4):46877.

[12] Ozaslan A, Karadayi B, Kolusayin MO, et al. Predictive role of hand and foot dimensions in stature estimation. Rom J Leg Med. 2012; 20(1):41-46.

[13]Chiari L, Rocchi L, Cappello A. Stabilometric parameters are affected by anthropometry and foot placement. Clin Biomech. 2002; 17(9-10):666-77.

[14] Tsigilis N, Douda H, Tokmakidis SP. Testretest reliability of the eurofit test battery administered to university students. Percept Mot Skills. 2002; 95(3 PART 2):1295-1300.

[15]Özmen T, Güneş GY. Prepubertal Amatör Cimnastikçilerde Dinamik Denge, Dikey 
Sıçrama ve Gövde Stabilitesi Arasındaki İlişki. Spor Bilim Derg. 2017; 28(1):24-29.

[16] Plisky PJ, Gorman PP, Butler RJ, et al. The reliability of an instrumented device for measuring components of the star excursion balance test. N Am J Sports Phys Ther. 2009; 4(2):92-99.

[17]Lin MR, Hwang $\mathrm{HF}, \mathrm{Hu} \mathrm{MH}$, et al. Psychometric comparisons of the timed up and go, one-leg stand, functional reach, and Tinetti balance measures in communitydwelling older people. J Am Geriatr Soc. 2004;52(8):1343-48.

[18] Shubert TE, Schrodt LA, Mercer VS, et al. Are scores on balance screening tests associated with mobility in older adults? J Geriatr Phys Ther. 2006; 29(1):33-39.

[19]Haksever B, Düzgün İ, Yüce D, et al. Sağlıklı Bireylere Standart Denge Eğitiminin Dinamik, Statik Denge Ve Fonksiyonellik Üzerine Etkileri. Gazi Sağlık Bilim Derg. 2017; 2(3):40-49.

[20]Marks GC, Habicht JP, Mueller WH. Reliability, dependability, and precision of anthropometric measurements. The Second National Health and Nutrition Examination Survey 1976-1980. Am J Epidemiol. 1989; 130(3):578-87.

[21]Perissinotto E, Pisent C, Sergi G, et al. Anthropometric measurements in the elderly: age and gender differences. $\mathrm{Br} \mathrm{J}$ Nutr. 2002; 87(2):177-86.

[22] İşeri A, Arslan N. Estimated anthropometric measurements of Turkish adults and effects of age and geographical regions. Int $\mathbf{J}$ Ind Ergon. 2009; 39(5):860-65.

[23] Kaptoge S, Dalzell N, Loveridge N, et al. Effects of gender, anthropometric variables, and aging on the evolution of hip strength in men and women aged over 65. Bone. 2003; 32(5):561-70.
[24] Sertel Meyvaci S, Bamaç B, Duran B, et al. Effect of surgical and natural menopause on proximal femur morphometry in obese women. Ann Anat. 2020;227:151416.

[25] Sertel Meyvaci S, Kosif R, Bamaç B, et al. Evaluation of apertura piriformis and related cranial anatomical structures through computed tomography: Golden ratio. Folia Morphol. 2019; 78(4):839-46.

[26] Krishan K, Kanchan T, Passi N, et al. Stature estimation from the lengths of the growing foot-A study on North Indian adolescents. Foot. 2012; 22(4):287-93.

[27]Nor FM, Abdullah N, Mustapa AM, et al. Estimation of stature by using lower limb dimensions in the Malaysian population. $\mathbf{J}$ Forensic Leg Med. 2013; 20(8):947-52.

[28]Xu M, Hong Y, Li JX, et al. Foot morphology in chinese school children varies by sex and age. Med Sci Monit. 2018; 24:4536-46.

[29] Kanchan T, Krishan K, ShyamSundar S, et al. Analysis of footprint and its parts for stature estimation in Indian population. Foot. 2012; 22(3):175-180.

[30] Hatala KG, Dingwall HL, Wunderlich RE, et al. The relationship between plantar pressure and footprint shape. J Hum Evol. 2013; 65(1):21-28.

[31] Ozden H, Balci Y, Demirüstü C, et al. Stature and sex estimate using foot and shoe dimensions. Forensic Sci Int. 2005; 147(23):181-84.

[32][Hackman L, Davies CM, Black S. Age Estimation Using Foot Radiographs from a Modern Scottish Population. J Forensic Sci. 2013; 58 (SUPPL. 1):146-50.

[33] Inamori-Kawamoto O, Ishikawa T, Michiue $\mathrm{T}$, et al. Possible application of CT morphometry of the calcaneus and talus in forensic anthropological identification. Int $\mathbf{J}$ Legal Med. 2016; 130(2):575-85. 
[34] Kanaani JM, Mortazavi SB, Khavanin A, et al. Foot Anthropometry of 18-25 Years Old Iranian Male Students. Asian J Sci Res. 2010; 3(1):62-69.

[35] Sanli SG, Kizilkanat ED, Boyan N, et al. Stature estimation based on hand length and foot length. Clin Anat. 2005; 18(8):589-96.

[36] Hemy N, Flavel A, Ishak NI, et al. Sex estimation using anthropometry of feet and footprints in a Western Australian population. Forensic Sci Int. vol 2013; 231(1-3):402.e1-402.e6.

[37]Akşit T, Özkol MZ, Vural F, et al. Contribution of anthropometric characteristics to critical swimming velocity and estimated propulsive force. J Phys Educ Sport. 2017; 17(1):212-18.

[38] Arazi H, Mirzaei B, Nobari H. Anthropometric profile, body composition and somatotyping of national Iranian crosscountry runners. Turkish J Sport Exerc. 2015; (17)2:35.

[39] Cavia M, Moreno A, Fernández-Trabanco B, et al. Anthropometric characteristics and somatotype of professional soccer players by position. J Sport Med Ther. 2019; 4(4):07380.

[40] Alonso AC, Luna NMS, Mochizuki L, et al. The influence of anthropometric factors on postural balance: The relationship between body composition and posturographic measurements in young adults. Clinics. 2012; 67(12):1433-41.

[41] Keionen P, Kauranen K, Vanharanta H. The relationship between anthropometric factors and body-balancing movements in postural balance. Arch Phys Med Rehabil. 2003; 84(1):17-22.

[42] Moein E, Movaseghi F. Relationship between some anthropometric indices with dynamic and static balance in sedentary female college students. Turk J Sport Exe. 2016; 18(1):45-49.

[43]Hansen MS, Dieckmann B, Jensen K, et al. The reliability of balance tests performed on the kinesthetic ability trainer (KAT 2000). Knee Surgery Sport Traumatol Arthrosc. 2000; 8(3):180-85. 